
\title{
R Research Soure \\ Effect of Pyrolytic Carbon Interphase on Mechanical Properties of mini T800-C/SiC Composites
}

\section{Donglin Zhao}

Northwestern Polytechnical University

\section{Tong Guo}

Shanghai Engineering Center for Microsatellites

X.M. Fan ( $\square$ fanxiaomeng@nwpu.edu.cn )

Northwestern Polytechnical University

\section{Chao Chen}

Northwestern Polytechnical University School of Science

\section{Yue $\mathrm{Ma}$}

Northwestern Polytechnical University

\section{Research Article}

Keywords: C/SiC, T800 carbon fiber, PyC interphase, Tensile strength, Weibull modulus

Posted Date: October 20th, 2020

DOI: https://doi.org/10.21203/rs.3.rs-46865/v2

License: (c) (i) This work is licensed under a Creative Commons Attribution 4.0 International License. Read Full License 


\title{
Effect of Pyrolytic Carbon Interphase on Mechanical Properties of mini T800-C/SiC Composites
}

\author{
Donglin Zhao ${ }^{1}$, Tong $\mathrm{Guo}^{2}$, Xiaomeng $\mathrm{Fan}^{1 *}$, Chao Chen ${ }^{1 *}$, Yue Ma ${ }^{1}$
}

1. Science and Technology on Thermostructure Composites Materials Laboratory, Northwestern Polytechnical University, Xi'an, Shaanxi, 710072, PR China

2. Innovation Academy for Microsatellites of CAS, Shanghai, 201203, PR China fanxiaomeng@nwpu.edu.cn, superchen@nwpu.edu.cn

\section{ABSTRACT}

The effect of pyrolytic carbon (PyC) thickness on the tensile property of mini T800-carbon fiber reinforced $\mathrm{SiC}$ matrix composites (mini-C/SiC) was studied in this work. PyC interphase was prepared by chemical vapor infiltration (CVI) process using $\mathrm{C}_{3} \mathrm{H}_{6}-\mathrm{Ar}$ as gas source, and the PyC thickness was adjusted from 0 to $400 \mathrm{~nm}$, then the SiC matrix was prepared by CVI process using methyltrichlorosilane (MTS)- $\mathrm{H}_{2}-\mathrm{Ar}$ as precursor and gas source. The results showed that the tensile strength of mini-C/SiC increased first and then decreased with the increase of the PyC thickness. When the thickness of PyC was $100 \mathrm{~nm}$, the average strength reached the maximum value of $393 \pm 70 \mathrm{MPa}$. The Weibull modulus increased from 2.0 to 8.06 with the increase of PyC thickness, the larger the Weibull modulus, the smaller the dispersion, which indicated that the regulation of PyC thickness is conducive to improve tensile properties.

Keywords: C/SiC; T800 carbon fiber; PyC interphase; Tensile strength; Weibull modulus

\section{Introduction}

Continuous carbon fiber reinforced silicon carbide ceramic matrix composite $(\mathrm{C} / \mathrm{SiC})$ has been widely used in aviation, aerospace and high-speed braking due to its advantages of low density, high temperature resistance, high specific strength and high specific modulus[1]. The United States and Europe have successfully applied $\mathrm{C} / \mathrm{SiC}$ composites in the fields of thermal protection system[6], aerospace propulsion system[8] and optical system[11].

The property of carbon fiber is important for the mechanical properties of $\mathrm{C} / \mathrm{SiC}$. 
At present, the widely used $\mathrm{C} / \mathrm{SiC}$ composites are mostly reinforced with $\mathrm{T} 300$-carbon fiber[14]. Compared with T300 carbon fiber, the empolyment of high strength carbon fiber like T800-carbon fiber is beneficial to further improve the mechanical properties of composites[15]. Some research has been carried out for high strength fiber reinforced $\mathrm{C} / \mathrm{SiC}$ composite materials, such as three dimensional braided $\mathrm{T} 800 \mathrm{C} / \mathrm{SiC}$ composite was prepared, and its bending strength is 511.5 MPa[16]. For T300-carbon fiber, the Young's modulus is $230 \mathrm{GPa}$ and coefficient of thermal expansion (CTE) is $-0.41 \times 10^{-6} / \mathrm{K}$. Compared with T300-carbon fiber, T800-carbon fiber has higher Young's modulus (300 GPa) and CTE $\left(-0.56 \times 10^{-6} / \mathrm{K}\right)$, and thus the modulus and CTE match between T800-carbon fiber and $\mathrm{SiC}$ matrix, which Young's modulus is $450 \mathrm{GPa}$ and coefficient of thermal expansion is $4.6 \times 10^{-6} / \mathrm{K}[17][18]$, should be re-adjusted by the interphase optimization. Up to now, the research focused on the properties of composites, and it is lack of study on the interphase optimization of T800-C/SiC.

The interphase is crucial to tailor the modulus and CTE match between fiber and matrix. The interphase plays the role of crack deflection and the load transfer from matrix to fiber, and these two roles are usually balanced to optimize the strength and toughness. PyC has a common component with carbon fiber and $\mathrm{SiC}$ matrix, and has high chemical stability, so there is no interfacial chemical reaction in the high temperature chemical environment of $\mathrm{CMC}$ preparation. In addition, PyC has low modulus (35 GPa), which can effectively alleviate the thermal expansion mismatch during high temperature preparation, and the shear strength of $\mathrm{PyC}$ is low, which is beneficial to control the interfacial bonding strength. the $\mathrm{PyC}$ is the most widely used interphase material for $\mathrm{CMC}[19]$. As reported, for T300-carbon fiber reinforced $\mathrm{C} / \mathrm{SiC}$ compositesError! Reference source not found., the PyC interphase thickness and crystallization were usually adjusted, and the optimized thickness was around $200 \mathrm{~nm}$. While for the T800-carbon fiber, it has a different microstructure with T300-carbon fiber. The T300-carbon fiber has obvious skin core structure, while T800 fiber has uniform and dense structure[23], leading to the interphase with different required thickness. So, it is essential to carry out the study on the optimization of interphase for $\mathrm{T} 800-\mathrm{C} / \mathrm{SiC}$ 
In this work, the mini $\mathrm{T} 800-\mathrm{C} / \mathrm{SiC}$ was employed, and the PyC interphase thickness was adjusted by controlling the deposition time. The effect of PyC interphase thickness on the tensile properties of mini $\mathrm{T} 800-\mathrm{C} / \mathrm{SiC}$ composites were characterized.

\section{Experimental procedures}

\subsection{Materials preparation}

T800 carbon fibers (QZ5526, Weihai Tuozhan Fiber Co. LTD, China) were employed, and the main performance indicators are shown in Table 1.

Table 1 Parameters of T800 carbon fiber

\begin{tabular}{ccccccc}
\hline $\begin{array}{c}\text { Tow } \\
\text { sizes }\end{array}$ & $\begin{array}{c}\text { Tensile } \\
\text { Strength } \\
(\mathrm{MPa})\end{array}$ & $\begin{array}{c}\text { Tensile } \\
\text { Modulus } \\
(\mathrm{GPa})\end{array}$ & $\begin{array}{c}\text { Failure } \\
\text { Strain } \\
(\%)\end{array}$ & $\begin{array}{c}\text { Density } \\
\left(\mathrm{g} / \mathrm{cm}^{3}\right)\end{array}$ & $\begin{array}{c}\text { Diameter } \\
(\mu \mathrm{m})\end{array}$ & $\begin{array}{c}\text { Carbon } \\
\text { content } \\
(\%)\end{array}$ \\
\hline 6000 & 5500 & 300 & 1.8 & 1.8 & 5.2 & 96 \\
\hline
\end{tabular}

First, a single continuous carbon fiber bundle should be wound on the mold with appropriate strength to ensure that the fiber bundle was stretched without being damaged. PyC interphase was prepared on carbon fiber surface by chemical vapor infiltration (CVI) process using $\mathrm{C}_{3} \mathrm{H}_{6}-\mathrm{Ar}$ as gas source and then the $\mathrm{PyC}$ interphase was heat-treated by $1800{ }^{\circ} \mathrm{C}$ for $1 \mathrm{~h}$ under vacuum. The infiltration time of $\mathrm{PyC}$ interphase was chosen as $0,40,80$ and $160 \mathrm{~h}$, to control the interphase thickness. After that, $\mathrm{SiC}$ matrix was deposited by CVI using methyltrichlorosilane (MTS) $-\mathrm{Ar}-\mathrm{H}_{2}$ as precursor at $3 \mathrm{kPa}$. After the infiltration of $\mathrm{SiC}$ matrix for $160 \mathrm{~h}$, the mini T800-C/SiC composites with different thickness PyC interphase were obtained. According to the different infiltration time of $\mathrm{PyC}$ interphase, the samples were named as samples S0, S1, S2 and S3, respectively.

\subsection{Characterization}

The as-prepared sample for the tensile testing was shown in Fig. 1, which was prepared by gluing the mini $\mathrm{T} 800-\mathrm{C} / \mathrm{SiC}$ specimen into the grip area with epoxy resin. The tensile strengths of samples were measured by mechanical testing machine (INSTRON-3345, INSTRON CORPORATION, USA) at room temperature, the span 
and loading rate are $50 \mathrm{~mm}$ and $0.2 \mathrm{~mm} / \mathrm{min}$ according to ASTM D3379-75. For each assembles, sixteen specimens were tested. The morphology and fracture surface of samples were observed with scanning electron microscope (SEM, S-4700, Hitachi, Japan).

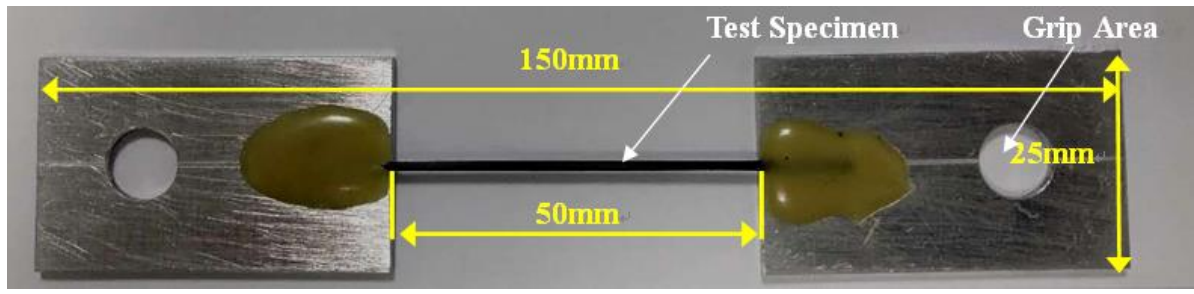

Fig.1 Macroscopic image of mini T800-C/SiC sample

\section{Results and discussion}

Fig. 2 present the SEM images of samples S0, S1, S2 and S3. As shown in Fig. 2 (a), the SiC matrix was directly deposited on the surface of carbon fiber for sample S0. The PyC interphase was prepared between the $\mathrm{SiC}$ matrix and carbon fiber, and the interphase thicknesses of samples S1, S2 and S3 were 100, 200 and $400 \mathrm{~nm}$, as shown in Fig. 2(b-d). The SEM observations for interphase thickness had been carried out on every sample, and the arithmetic mean value of interphase thickness was calculated. It should be noted that, in order to make the data more concise and clear, the arithmetic mean value of interphase was normalized. 

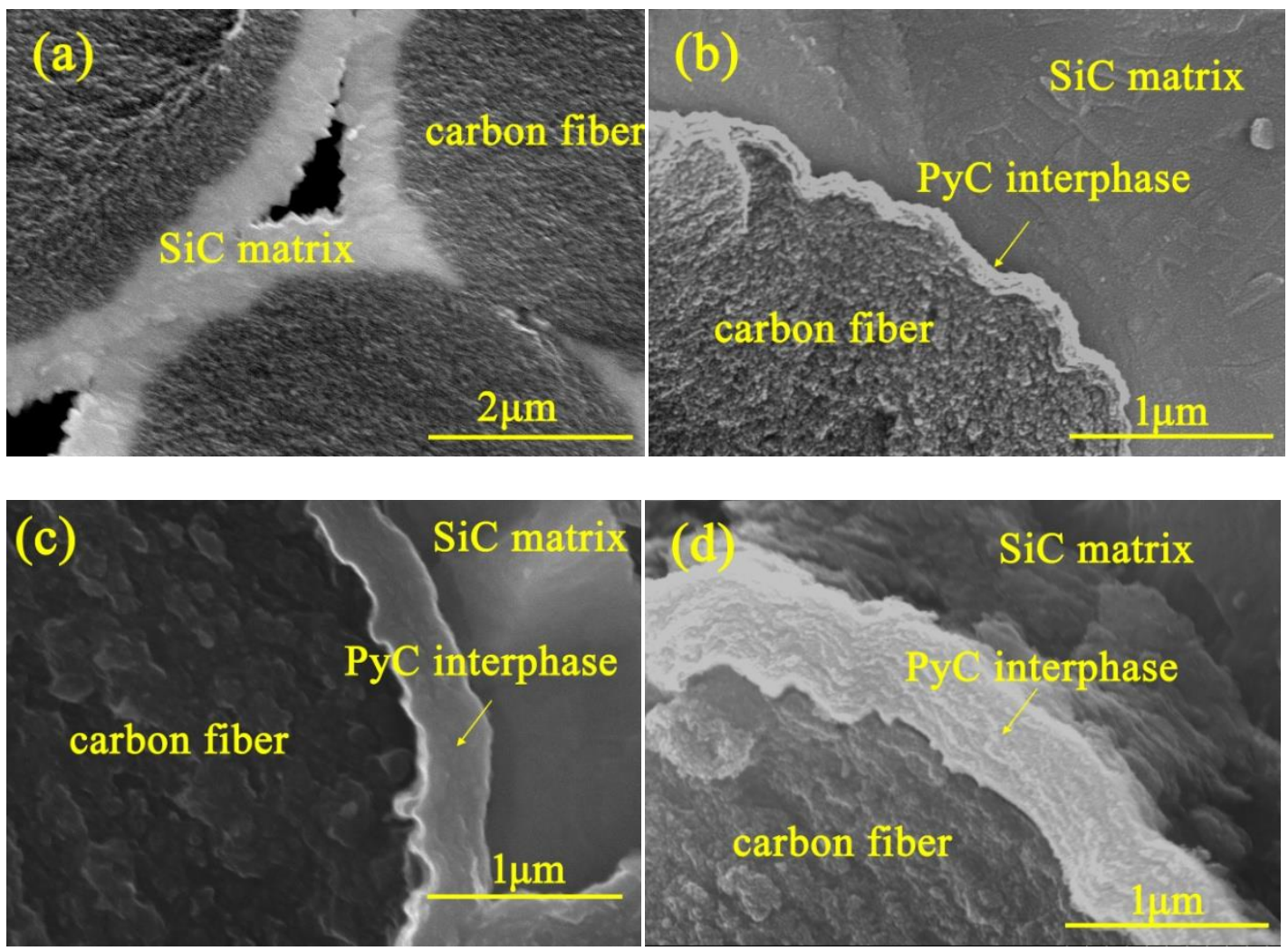

Fig.2 Microstructure of mini T800-C/SiC composite with different thickness PyC interface:

(a) sample S0, (b) sample S1,(c) Sample S2, (d) sample S3

The tensile properties of mini- $\mathrm{C} / \mathrm{SiC}$ composite were tested, and the stress-strain curves were shown in Fig. 3. Because there is no interphase to deflect the crack in sample S0, the matrix failed as soon as it cracked because of the penetration of the main crack, and brittle fracture occurred at low stress. The curves of sample S1, S2, S3 are nonlinear, revealing tough rupture. Samples S1, S2, S3 had a certain thickness of interphase, the cracks can be deflected, and interphase debonding and sliding occurred, so the samples showed "pseudo plastic" fracture.

The stress-strain curves of samples S1, S2 and S3 were divided into three stages. The first stage was the linear elastic stage. In this stage, the elastic deformation of the fiber and the matrix occurred simultaneously, and the tangent modulus of the curve remained unchanged. The second stage was nonlinear. There is a critical transition point after the linear elastic stage, where the critical transition point is the matrix cracking stress value. The critical transition points on the stress-strain curves of 
samples S1, S2 and S3 were calculated, and the corresponding matrix cracking stress are 212, 183 and $144 \mathrm{MPa}$, respectively. The results showed that with the increase of the PyC thickness, the matrix cracking stress decreased.

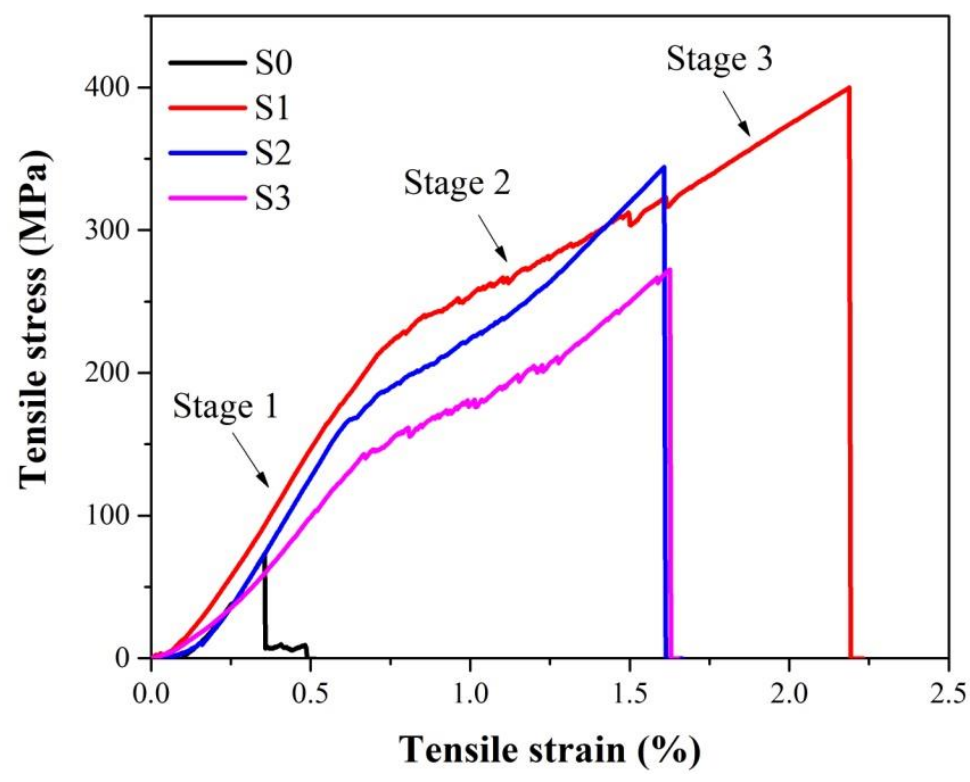

Fig. 3 Stress-strain curve of mini T800-C/SiC composites with different interphase thickness

After the critical transition point, the matrix cracks increased continuously. Because of the existence of weak PyC interphase between matrix and fiber, the cracks deflected and then the interphase de-bonding and sliding occured. With the increase of stress, the crack density increased, and gradually reached saturation, and the matrix stress no longer increased with the external load. Because of the thermal mismatch between the fiber and the matrix, there were cracks existing in the matrix of mini $\mathrm{T} 800-\mathrm{C} / \mathrm{SiC}$. In the first stage, the stress was too small for the crack to propagate, but in the second stage, the cracks begin to expand and propagate when the stress exceeds the matrix cracking stress. In this stage, the tangent modulus of the curve decreased gradually due to the proliferation of matrix cracks, showing zigzag shape. In the third stage, the stress-strain curve showed a linear rise again. After the second stage, the applied stress began to be mainly carried by the fibers, and the tangent modulus of the curve increased again and remains unchanged. With the increase of the stress, the fibers began to fracture until the material failed.

3.2 Tensile strength distribution analysis 
Ceramic matrix composites are brittle materials, for fully reflect its strength characteristics, it is necessary to use random distribution to describe the strength. The two parameter Weibull distribution function can better describe the statistical distribution of strength for fiber reinforced composites. In order to obtain the dispersion and average tensile strength values of mini-C/SiC composite materials, it was firstly assumed that the tensile strength distribution was in line with the Weibull distribution function, and the distribution of tensile strength was calculated and analyzed using the two-parameter Weibull model[24]. Then kolmogorov-smirnov (k-s test) non-parametric test method was used to test the assumed distribution [28]. The Weibull distribution of two-parameter is generally expressed as:

$$
F(\sigma)=1-\exp \left[-\frac{V}{V_{0}}\left(\frac{\sigma_{i}}{\sigma_{0}}\right)^{m}\right]
$$

Where $f(\sigma)$ is the failure probability; $V$ is the effective test volume of the sample; $V_{0}$ is the reference volume; $\sigma_{i}$ is the applied stress; $\sigma_{0}$ is the size parameter $(\mathrm{MPa})$, which is the characteristic strength; $\mathrm{m}$ is the shape parameter, which is the Weibull modulus, which is used to characterize the dispersion degree of the strength, the lower the dispersion of the strength, the larger the Weibull modulus.

Setting $\mathrm{V}_{0}$ equal to $\mathrm{V}$, the simplified Weibull distribution function is as follows:

$$
F(\sigma)=1-\exp \left[-\left(\frac{\sigma_{i}}{\sigma_{0}}\right)^{m}\right]
$$

The parameters of Weibull distribution function are solved by graphic method. Two logarithmic transformations are performed on both sides of formula (2), and the following formula is obtained:

$$
\ln \ln \left(\frac{1}{1-F}\right)=m \ln \sigma_{i}-m \ln \sigma_{0}
$$

Where $\mathrm{F}$ is the empirical distribution of the data. Generally speaking, the empirical distribution function (EDF) of random samples is defined as a ladder function, as shown in the following formula: 


$$
F=\frac{i-0.5}{n}
$$

Where $\mathrm{n}$ is the number of specimens and $\mathrm{i}$ is the serial number of specimens.

The $\ln \sigma_{\mathrm{i}}$ and $\ln \ln (1 /(1-\mathrm{F}))$ are plotted as abscissa and ordinate respectively, and linear regression is carried out. The slope of the graph is the estimated value of $\mathrm{m}$, and the intercept is the estimated value of $-m \ln \sigma_{0}$. Thus, the estimated value of characteristic strength $\sigma 0$ can be calculated.

The average tensile strength can be expressed by the expected value of Weibull distribution, as shown in formula (2):

$$
E(\sigma)=\sigma_{0} \Gamma\left(1+\frac{1}{m}\right)
$$

Where $\Gamma$ is the gamma function.

According to the above methods, the tensile strength of all the samples was calculated and analyzed. The Weibull modulus $\mathrm{m}$ and the expected value of Weibull distribution $\mathrm{E}(\sigma)$ are obtained. Fig. 4 shows the parameters calculated by the two parameters Weibull distribution graphic method, and the calculation results of all samples are listed in Table 2.

(a)

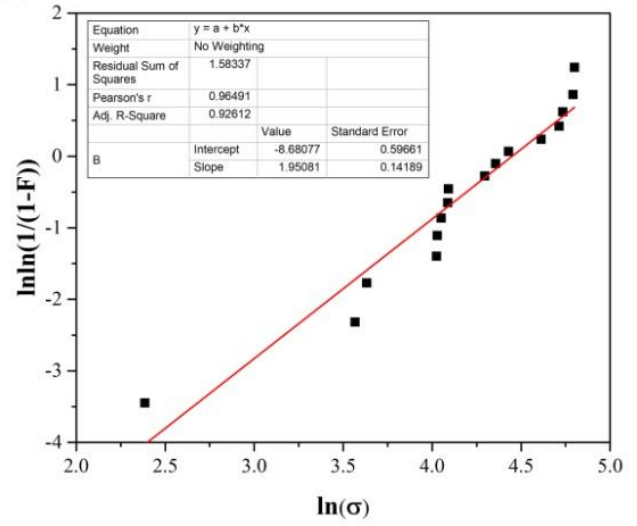

(b)

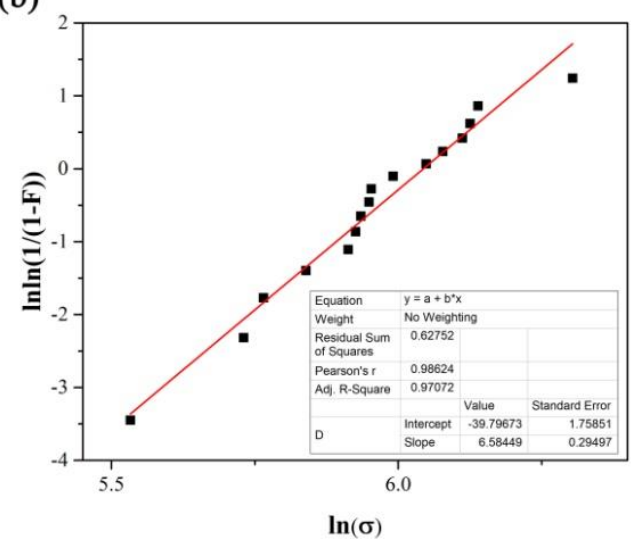


(c)

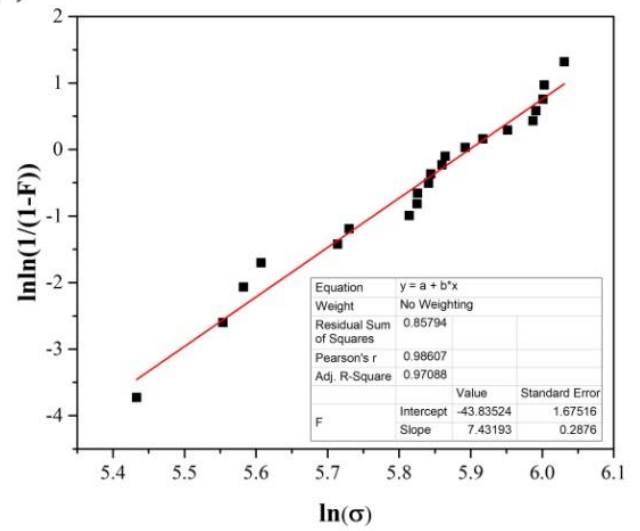

(d)

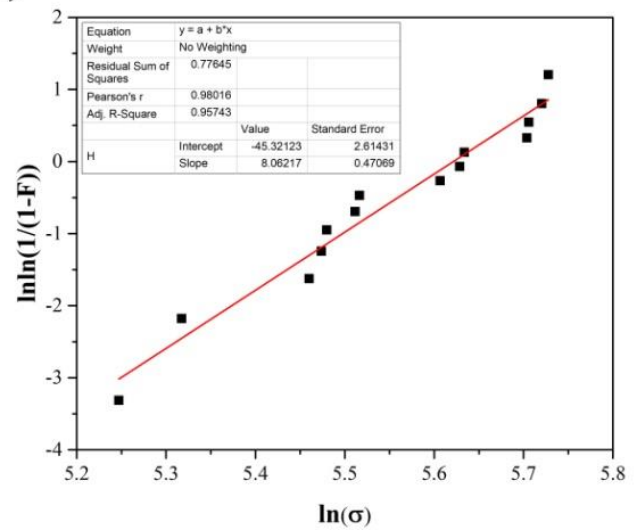

Figure 4 Two parameter Weibull distribution graphic method for parameter calculation:
(a) sample S0,
(b) sample $\mathrm{S} 1$,
(c) sample $\mathrm{S} 2$,
(d) sample S3

Table 2 Weibull distribution parameters and average strength of mini T800-C/SiC

\begin{tabular}{ccccc}
\hline Samples & S0 & S1 & S2 & S3 \\
\hline Fiber volume fraction (\%) & 20 & 20 & 20 & 20 \\
$\mathrm{~m}$ & 2.0 & 6.6 & 7.4 & 8.1 \\
$\sigma 0 / \mathrm{MPa}$ & 86 & 422 & 364 & 276 \\
$\mathrm{E}(\sigma) / \mathrm{MPa}$ & $76 \pm 6$ & $393 \pm 70$ & $342 \pm 53$ & $260 \pm 37$ \\
Normalized tensile strength $(\mathrm{MPa})$ & 80 & 380 & 368 & 304 \\
$\mathrm{~V}_{\mathrm{f}=20 \%}$ & & & &
\end{tabular}

The fiber volume fraction has a great influence on the mechanical properties of the composite. In order to eliminate the influence of different fiber volume fraction on the tensile strength, it is necessary to normalize the obtained tensile strength value and unify the fiber volume fraction to $20 \mathrm{vol} . \%$. The normalization of the tensile strength for samples were 80, 380, 368 and $304 \mathrm{MPa}$.

It can be seen that the change of the average tensile strength and the normalized average tensile strength were similar. Both tensile strength increased first and then decreased with the increase of the PyC interface phase thickness. As shown in Table 2, the average tensile strength and the normalized average tensile strength of sample S1 was maximum, while the Weibull modulus increased with the increase of the PyC 
thickness. When the PyC thickness increased from 0 to $400 \mathrm{~nm}$, the Weibull modulus increased from 2.0 to 8.1 , which means that the dispersion of material strength was getting smaller and smaller, that is to say, increasing the PyC interface phase thickness is conducive to improving the mechanical property stability of mini T800-C/SiC.

The fracture morphology of mini $\mathrm{T} 800-\mathrm{C} / \mathrm{SiC}$ composites with different interphase thickness were shown in Fig. 4. The fracture morphology of sample S0 is very even (Fig. 5a), indicating the typical brittle fracture. Although there were several monofilament fibers extending a long distance from the fracture, which was not pullout under stress, but due to some fibers lack of matrix phase restraint and did not bear load. The typical brittle fracture also could be seen form Fig. 6(a). As shown in Fig. 5 (b-d), it can be seen that the fibers show multi-stage pull-out for samples S1, S2 and S3. Moreover, the pull-out length of the fiber increases with the increase of the interphase thickness. According to the shear lag model [30]:

$$
\frac{L_{c}}{d_{f}}=\frac{\sigma_{f u}}{2 \tau}
$$

Where Lc is the critical fiber length (Lc/2 is the fiber pull-out length), $d_{f}$ is the fiber diameter, $\sigma_{f u}$ is the fiber breaking strength, $\tau$ is the interface shear strength. It can be seen that with the increase of the interphase thickness, the interfacial shear strength decreases, the critical fiber length increases, and the fiber pull-out length increases Error! Reference source not found.. The results showed that the interfacial shear strength of sample S3 is lower than that of sample S1, which indicated that the too thick interfacial shear strength was too low to transfer the load to the fiber, which made the mechanical properties of mini T800-C/SiC composite decline.

After the test, the crack spacing of each fracture specimen was measured. For each kind of specimen, nearly 30 crack spacing had been counted, and then given the statistical value. All the photos were typical crack spacing of each specimen in Fig. 5. The surface morphology of mini T800-C/SiC composite was shown in Figure 6. There were a large number of transverse matrix cracks on the surface of S1, S2 and S3, which were perpendicular to the loading direction. As can be seen from Fig. 6(a), no matrix crack was observed in sample S0 except the main fracture crack. In the tensile 
process of mini $\mathrm{T} 800-\mathrm{C} / \mathrm{SiC}$, the equidistant crack would be formed on the $\mathrm{SiC}$ matrix. From Fig. 6(b-d), the spacing of saturated cracks of samples S1, S2 and S3 were about 94,106 and $185 \mu \mathrm{m}$ respectively. With the increase of the interphase thickness, the interface bonding became weaker, and the saturated crack spacing of the matrix was larger, which is consistent with the longer length of pull-out [31].
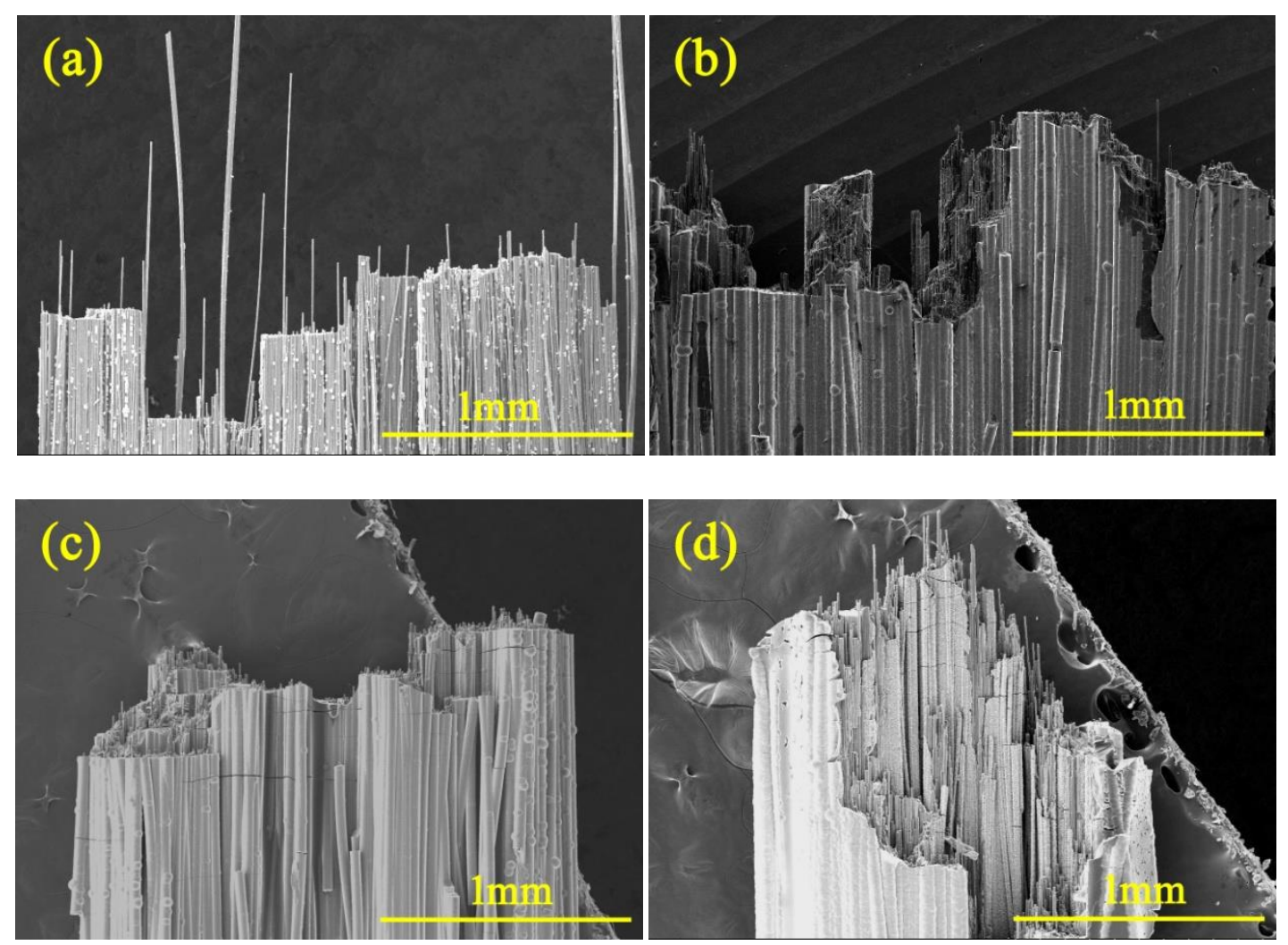

Fig. 5 Fracture morphology of mini T800-C/SiC composite: (a) sample S0, (b) sample S1,

(a) sample S2, (d) sample S3

There is an optimized thickness for the PyC interphase. It plays two roles, the first one is to deflect the cracks, and the second one is to transfer the load from the matrix to fiber. So, the optimization of PyC thickness is a balance between these two roles. As a summary, for the mini $\mathrm{T} 800-\mathrm{C} / \mathrm{SiC}$, it needs the appropriate PyC thickness to play the strengthening role of fibers. When the PyC thickness reach $100 \mathrm{~nm}$, it can effectively deflect the cracks, and also it has higher interfacial shear strength than that of samples S2 and S3, so it can be more effective to transfer the load, leading to the highest tensile strength in all four samples. 
The Weibull modulus is related to the stress distribution in the fiber bundles. The thermal residual stress always existed due to the thermal mismatch between carbon fiber and SiC matrix. There are 6000 filament in one bundle, and with the increase of PyC thickness, it can make the more uniform stress distribution on every filaments. So, the dispersion degree decreased, leading to the increase of Weibull modulus from 2.0 to 8.1 .
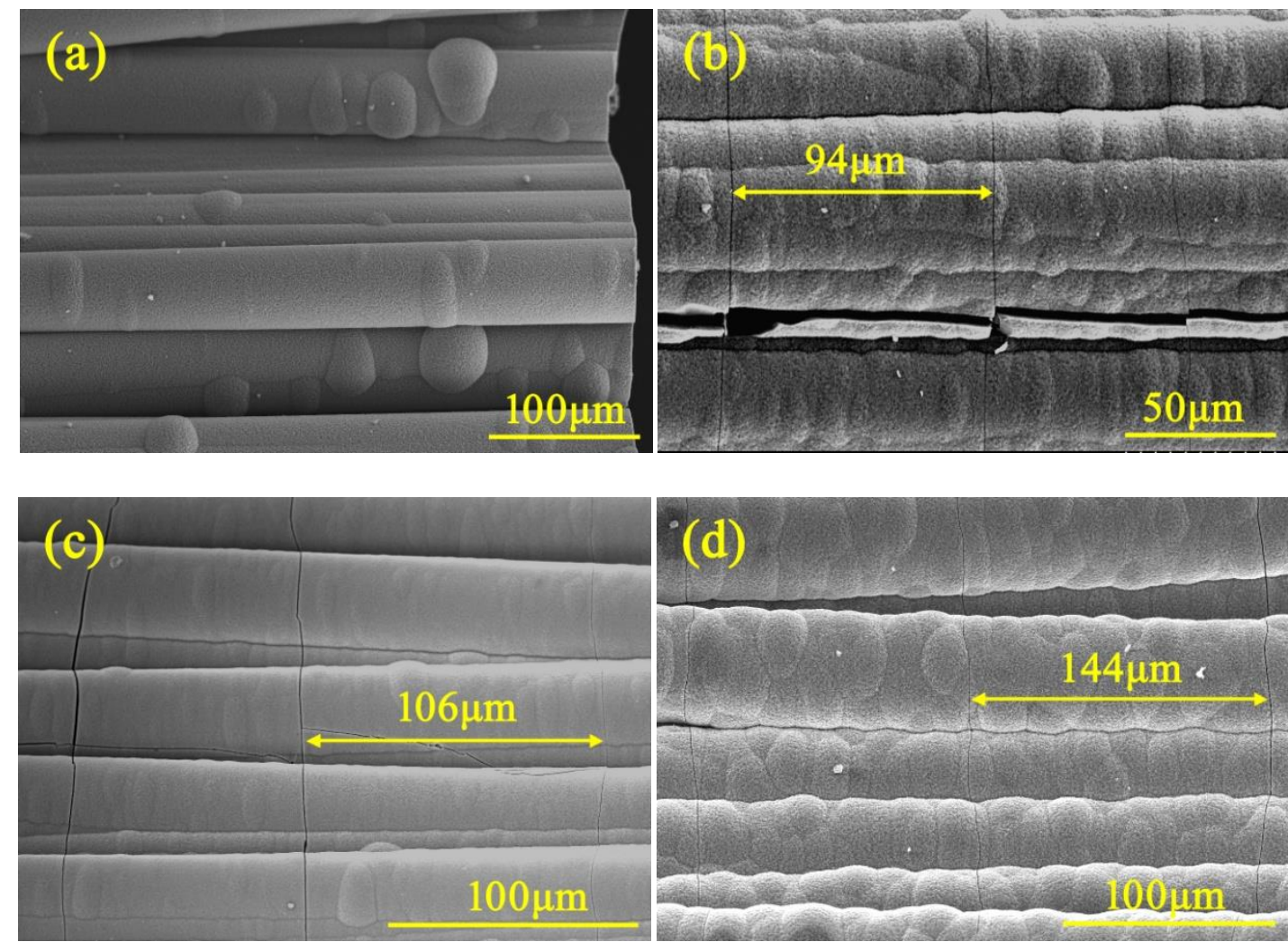

Fig. 6 the surface morphology of mini T800-C/SiC composite: (a) sample S0, (b) sample S1,

(c) Sample S2, (d) sample S3

\section{Conclusions}

In this paper, the mini $\mathrm{T} 800-\mathrm{C} / \mathrm{SiC}$ composites with different thickness of $\mathrm{PyC}$ interphase were prepared by CVI with T800-carbon fiber as reinforcement. The test results were analyzed by Weibull distribution model. The results showed that with the increase of PyC inter phase thickness, the tensile strength first increased and then decreased; when the thickness of PyC interface was $100 \mathrm{~nm}$, the average strength of the composite reached the maximum, which is $393 \mathrm{MPa}$. The Weibull modulus 
increased from 2.0 to 8.06 with the increase of the thickness of the PyC interface layer, which reduced the dispersion degree of the tensile strength of the mini-C/SiC composites. With the increase of the interphase thickness, the interface bonding was weaker, the pull-out length of the fiber was longer and the saturated crack spacing of the matrix was larger, leading to the decrease of the tensile strength.

\section{Acknowledgements}

This work was supported by the National Natural Science Foundation of China (Project Nos. 51702261, 51821091 and 51802263), the Natural Science Foundation of Shaanxi Province (Project No. 2019JQ-634), and the Fundamental Research Funds for the Central Universities.

\section{References}

[1] Jun Liu, Yili Pan, Wei Li, Yan Wei, Hui Li. Research on application of C/SiC composite in high-energy HAN-based thruster. Journal of Rocket Propulsion, 2017, 43(05):63-68.

[2] Tao Nie, Weiqiang Liu. Application of $\mathrm{C} / \mathrm{SiC}$ composites in thermal protection system of nose-cone. Computer Simulation, 2013, 30(9):109-112.

[3] Kumar S, Kumar A, Sampath K, et al. Fabrication and erosion studies of C-SiC composite Jet Vanes in solid rocket motor exhaust. Journal of the European Ceramic Society, 2011, 31(13):2425-2431.

[4] Gadow R, Speicher M. Multilayer C/SIC composites for automotive brake systems. Ceramic Materials and Components for Engines. Weinheim, Germany: Wiley-VCH Verlag GmbH, 2007, 565-570.

[5] Xiaojuan Zhu, Yingwei Xia. Application of $\mathrm{C} / \mathrm{SiC}$ composites in space optical system abroad. Aerospace Materials \& Technology, 2013, 43(4):20-23.

[6] M.lmuta, J.Gotoh. Development of high temperature materials including CMCs for space application. Key Engineering Materials, 1999(164/165): 439-444.

[7] Pfeiffer, H, Peetz, K. All-Ceramic body flap qualified for space flight on X38. 34th COSPAR Scientific Assembly, 2002.

[8] G. UHRIG. Composite technologies development status for scramjet applications. Aiaa/cira International Space Planes \& Hypersonics Systems \& Technologies 
Conference, 2005.

[9] F. Olufsen, E. Ørbekk, F. Olufsen. Application of CMC materials in rocket propulsion. advances in high temperature ceramic matrix composites and materials for sustainable development. Ceramic Transactions, 2017.

[10]Xiaowei Zhang. Ceramic matrix composite expands the application in aero-engine. 2015 (9th) International Forum on Composite Applications of Commercial Aircraft, 2015.

[11]Ulrich Papenburg, Wilhelm Pfrang, G. S. Kutter, et al. Optical and optomechanical ultralightweight $\mathrm{C} / \mathrm{SiC}$ components. Spies International Symposium on Optical Science, 1999.

[12]Kaneda H , Naitoh M , Nakagawa T , et al. Manufacturing and optical testing of $800 \mathrm{~mm}$ lightweight all $\mathrm{C} / \mathrm{SiC}$ optics. Proceedings of Spie the International Society for Optical Engineering, 2013, 8837.

[13]Matthias Kroedel, G. S. Kutter, Michael Deyerler,et al. Short carbon-fiber-reinforced ceramic-Cesic-for optomechanical applications. International Symposium on Optical Science \& Technology, 2002.

[14]Litong Zhang. Fiber-toughened silicon carbide ceramic composites-Simulation, characterization and design. Chemical Industry Press, 2009.

[15]Hongxing Gu. Characterization of domestic T800 carbon fiber and Study on properties of resin matrix composite. Xi'an China. Xi'an Institute of Optics and Precision Mechanics, Graduate School of the Chinese Academy of Sciences, 2015

[16]Zhou Xingui, You Yu Yu, Haijiao Yang, Jiangao Huang Zelan. Effects of carbon fiber $\mathrm{CVD} \mathrm{SiC}$ coatings on mechanical properties of $\mathrm{C} / \mathrm{SiC}$ composites. Rare metal materials and engineering, 2008, 37(z1): 32-35.

[17]X. Ma, X. Yin, X. Fan, X. Sun, L. Yang, F. Ye, L. Cheng. Microstructure and properties of dense Tyranno-ZMI SiC/SiC containing Ti3Si(Al)C2 with plastic deformation toughening mechanism, J. Eur. Ceram. Soc, 38 (4) (2018):1069-1078.

[18] Y. Wang, L. Zhang, L. Cheng, H. Mei, J. Ma. Characterization of tensile behavior 
of a two-dimensional woven carbon/silicon carbide composite fabricated by chemical vapor infiltration. Mater. Sci. Eng. A, 497 (2008) :295-300.

[19]Naslain R. Design, preparation and properties of non-oxide CMCs for application in engines and nuclear reactors: an overview. Composites ence \& Technology, 2004, 64(2):155-170.

[20]Hongfeng Yin, Yongdong Xu, Laifei Cheng. Effect of interphase on properties of carbon fiber reinforced silicon carbide composites. Journal of the Chinese Ceramic Society, 2000, 28 (001): 1-5.

[21]Xiangting Liu. The process optimization research of pyrolytic carbon interface on carbon fiber reinforced silicon carbide composites. Beijing, China. Beijing University of Chemical Technology, 2013.

[22]Mei H, Bai Q L, Sun Y Y, et al. The effect of heat treatment on the strength and toughness of carbon fiber/silicon carbide composites with different pyrolytic carbon interphase thicknesses. Carbon, 2013, 57 (6): 288-297.

[23] Fu He. High performance carbon fiber precursor and dry jet wet spinning. Hi-Tech Fiber and Application, 2004(04):6-12.

[24]Chi Z, Chou T W, Shen G. Determination of single fibre strength distribution from fibre bundle testings. Journal of Materials Science, 1984, 19(10): 3319-3324.

[25] Weibull W. A statistical distribution function of wide applicability. Journal of Applied Mechanics, 1951, 13 (2): 293-297.

[26]Fok S L. Mitchell B C, Smart J, et al. A numerical study on the application of the Weibull theory to brittle materials. Engineering Fracture Mechanics, 2001, 68 (10): 1171-1179.

[27]Dassios K G, Steen M, Filiou C. Mechanical properties of alumina Nextel ${ }^{\text {TM }} 720$ fibres at room and elevated temperatures: tensile bundle testing. Materials Science \& Engineering A, 2003, 349(1-2):63-72.

[28]Xizhi Wu, Bojuan Zhao. Nonparametric statistical methods. China Statistics Press, 2013.

[29]Conover W J , Nuohua Kang, Hengjian Cui. Practical nonparametric statistics. People's post and Telecommunications Press, 2006, 356-388.

[30]Cao X, Yin X, Fan X, et al. Effect of PyC interphase thickness on mechanical behaviors of $\mathrm{SiBC}$ matrix modified $\mathrm{C} / \mathrm{SiC}$ composites fabricated by reactive melt 
infiltration. Carbon, 2014, 77:886-895.

[31] Hsueh C H , Rebillat F , Lamon J , et al. Analyses of fiber push-out tests performed on Nicalon/SiC composites with tailored interfaces. Composites Engineering, 1995, 5(10-11):1387-1401.

[32]Jun Zhang, Yongdong Xu, Litong Zhang, Laifei Cheng, The matrix crack spacing distribution of 3D C/SiC composites. Journal of aeronautical materials. 2003, 23(3)11-14. 


\section{Figures}

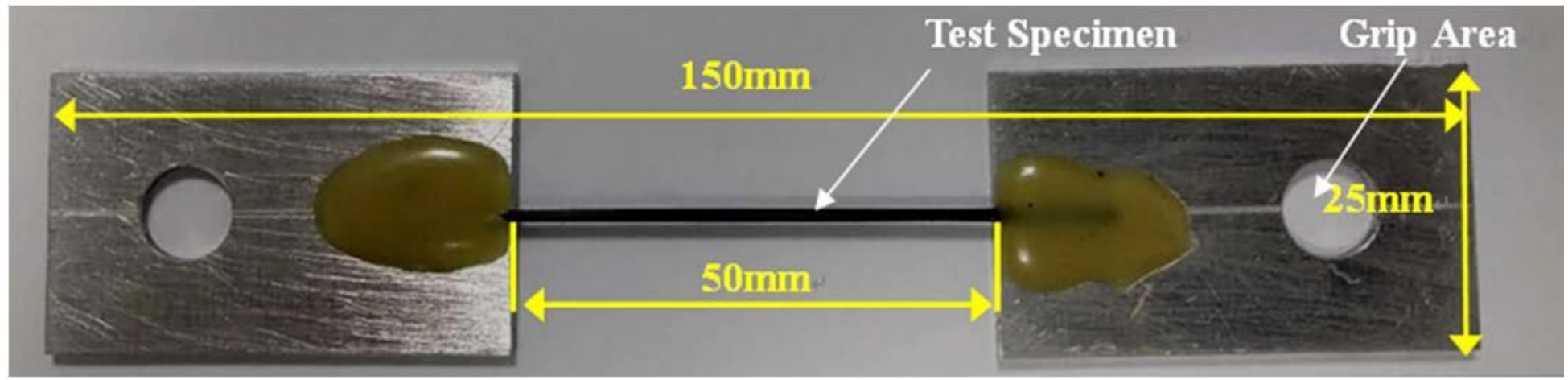

Figure 1

Macroscopic image of mini T800-C/SiC sample

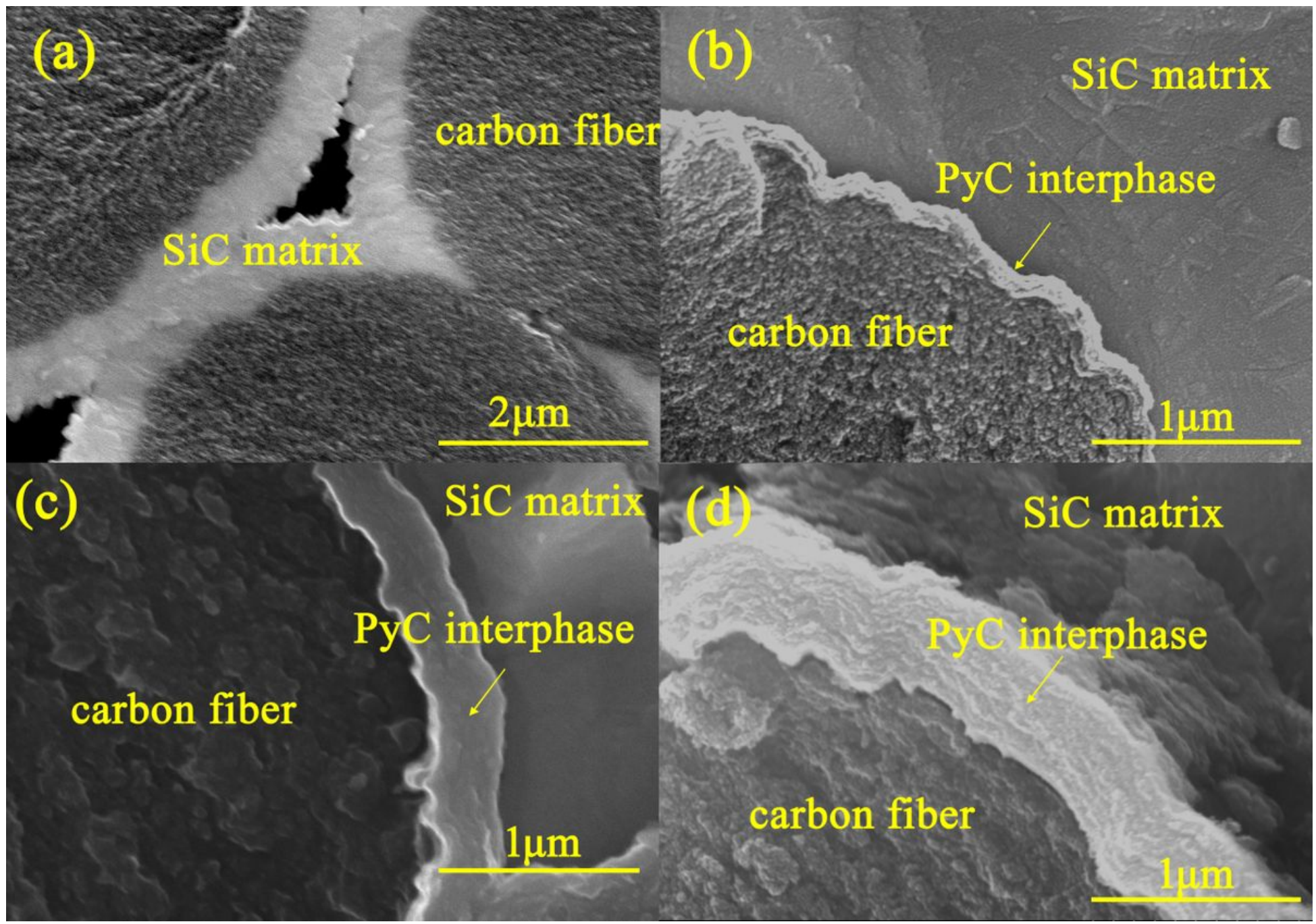

Figure 2

Microstructure of mini T800-C/SiC composite with different thickness PyC interface: (a) sample S0, (b) sample S1,(c) Sample S2, (d) sample S3 


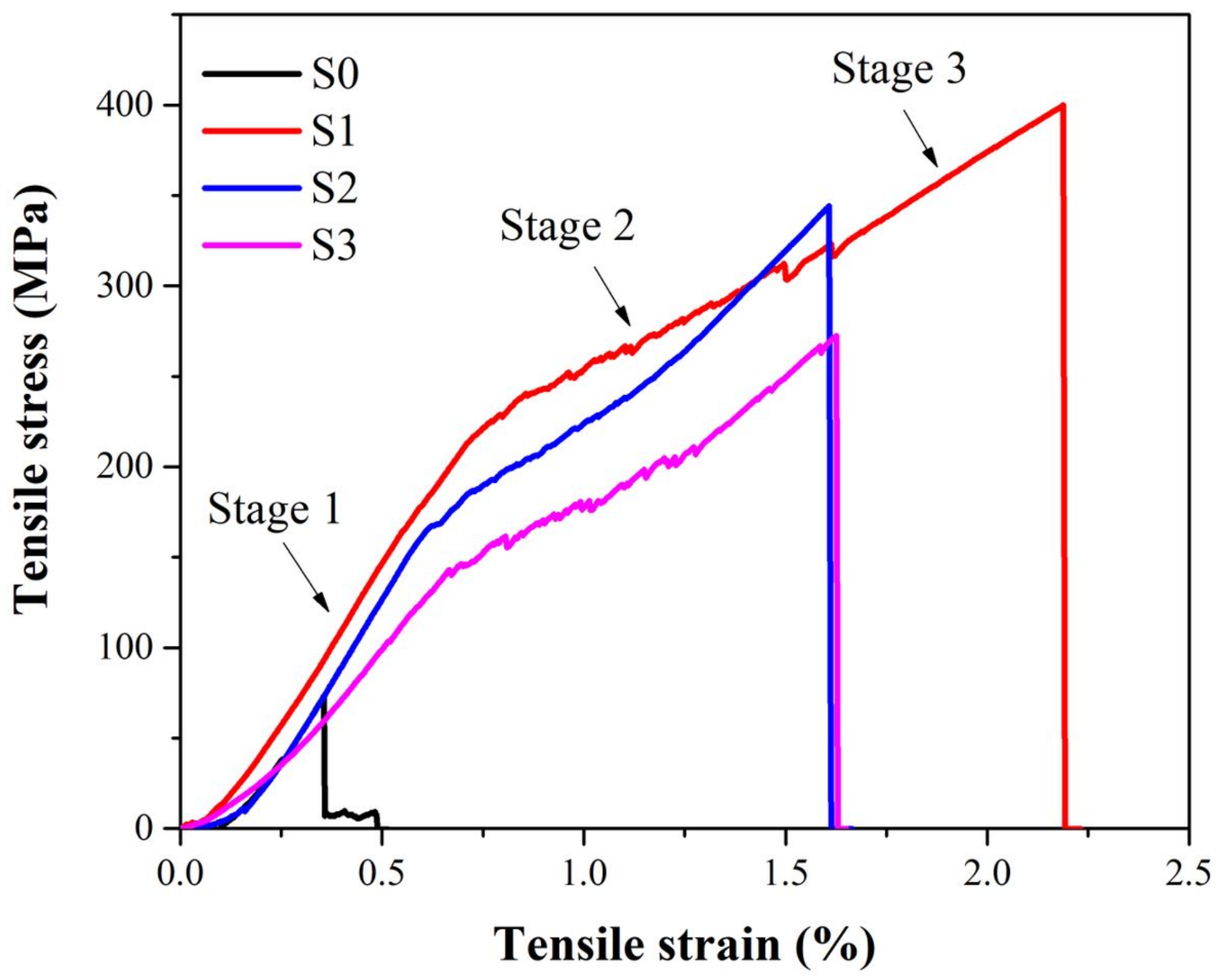

Figure 3

Stress-strain curve of mini T800-C/SiC composites with different interphase thickness 
(a)

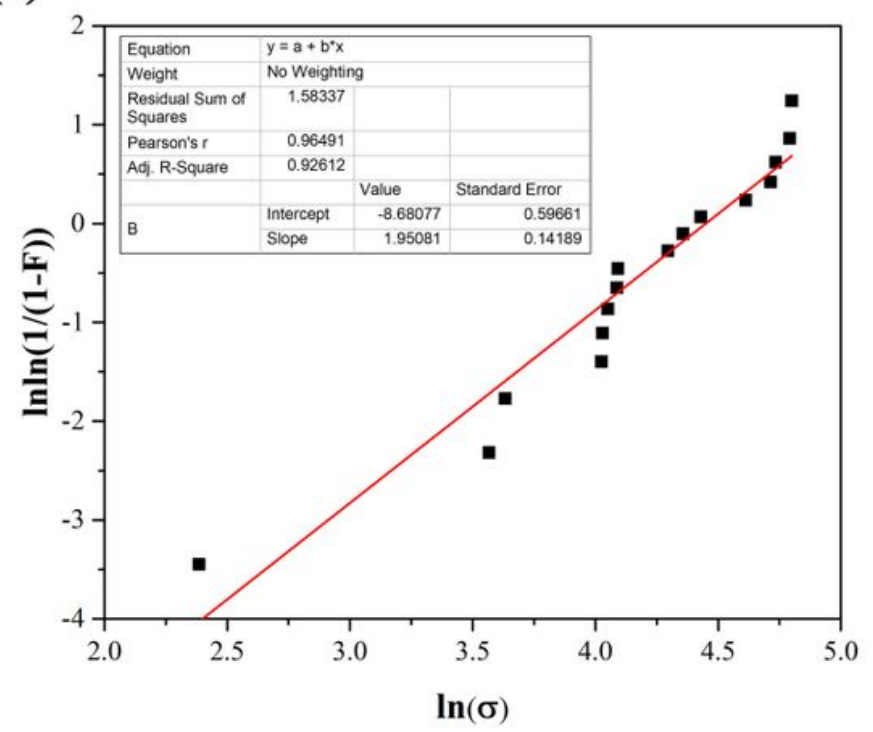

(c)

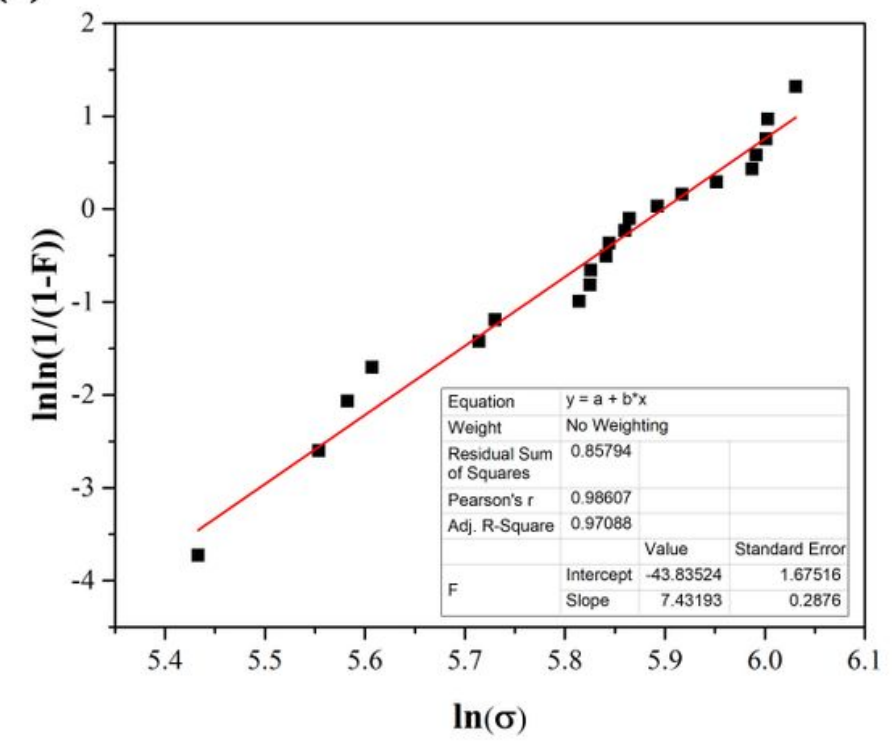

(b)

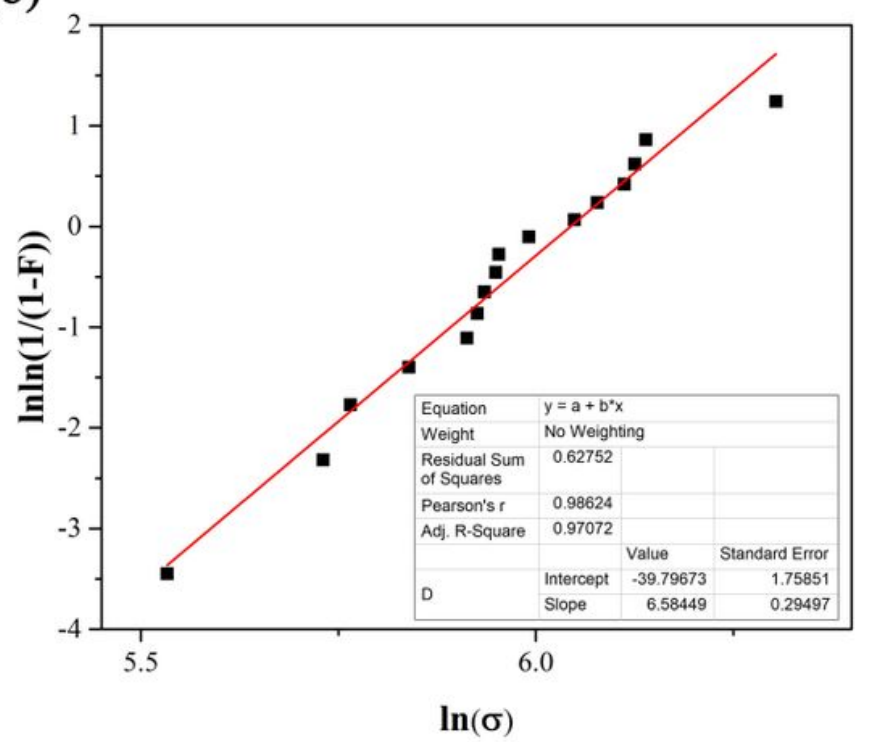

(d)

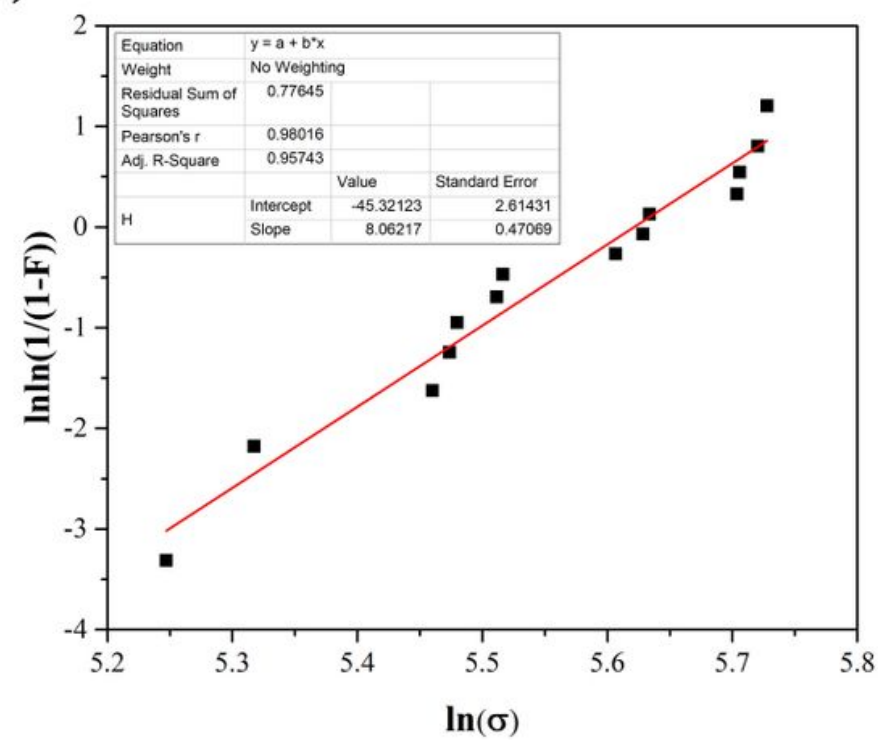

Figure 4

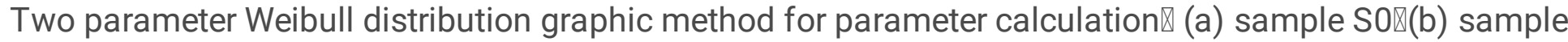
S1区(c) sample S2『(d) sample S3 


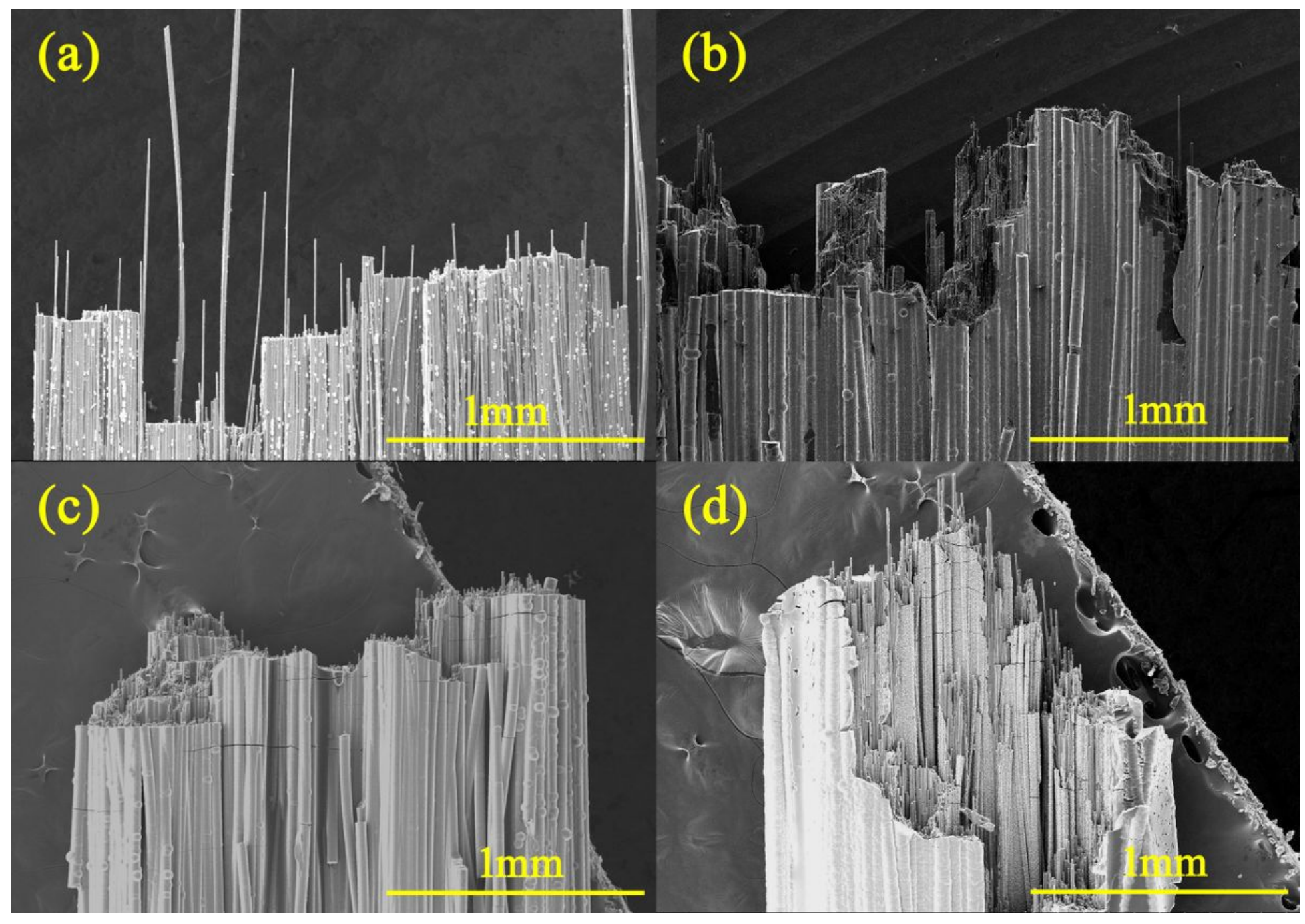

Figure 5

Fracture morphology of mini T800-C/SiC composite: (a) sample S0, (b) sample S1, (a) sample S2, (d) sample S3 


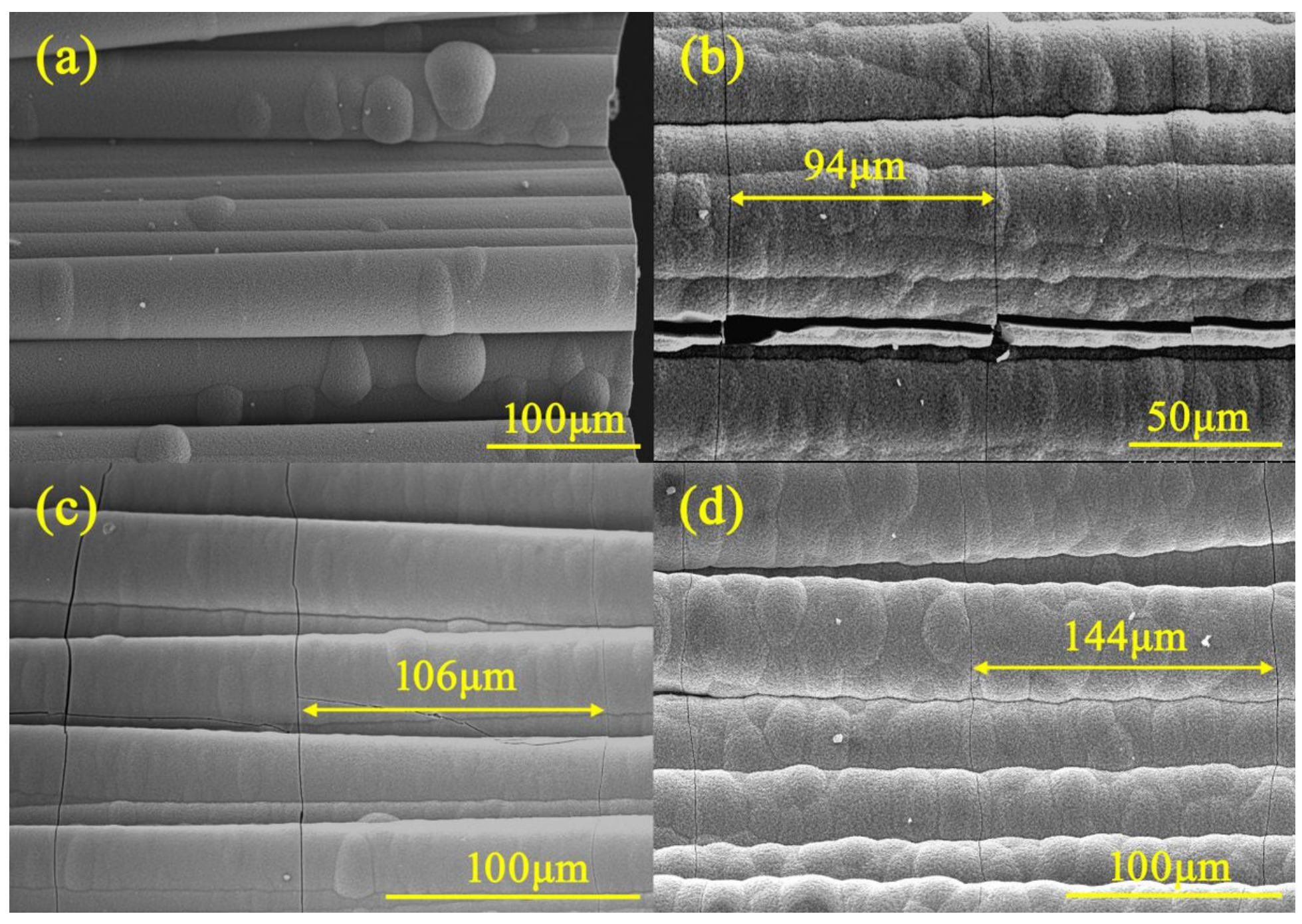

Figure 6

the surface morphology of mini T800-C/SiC composite: (a) sample S0, (b) sample S1, (c) Sample S2, (d) sample S3 